\title{
The Need for Medical Insurance Companies to look at Psychiatric Care
}

\author{
Pragya Lodha ${ }^{1}$, Avinash De Sousa ${ }^{2}$ \\ ${ }^{1}$ Research Assistant and Clinical Psychologist, Desousa Foundation, Mumbai. \\ ${ }^{2}$ Founder Trustee and Consultant Psychiatrist, Desousa Foundation, Mumbai. \\ Corresponding Author : Pragya Lodha \\ E-mail: pragya6lodha@gmail.com
}

Mental health is a challenge for policy makers, equally so in developed and first-world nations. It is certainly true for India considering the persistence of draconian laws that date back to the Victorian age. The burden of psychiatric care is experienced terms of economic cost, family burden, disability and unemployment in India [1]. The National Mental Health survey [2] shows that median out-of-pocket expenditure per month on mental healthcare was approximately INR 1000 to 1500 . Though, medical Insurance is available for virtually most of the medical problems that plague the human race, there is a profound neglect of medical insurance when it comes to psychiatric disorders and psychological problems [3]. For years, medical insurance companies have shunned away psychiatric disorders from their list of medical conditions where patients can avail of insurance.

The reasons claimed for the same are many -

- Psychiatric disorders are lifelong conditions where the treatment costs are high and the pattern of prescribing medication and treatment costs and styles vary hugely between professionals. There is also a difference in prescribing psychiatric medications between different practitioners that may vary from mono-pharmacy to rational poly-pharmacy. This leads to huge discrepancy in bills and treatment costs that do not allow medical insurance companies to judge costs of premiums and other costs [4].

- The heterogeneity of mental health professionals involved in mental health carepsychiatrists, psychologists, counsellors, social workers in mental health- have varied approach to treatment, thus creating a diverse treatment pool where the implicated cost varies with the nature of treatment provided.

- Insurance coverages fail to cover the payment for hospital versus non-hospital charges, private versus public hospital charges for mental health care treatment. The sliding bar of payment varies greatly among private practitioners as well which may also ascertain the non-coverage [5].

- There are also a number of psychiatric treatments like transcranial direct current stimulation, repetitive transcranial magnetic stimulation and electroconvulsive therapy where the cost varies across practitioners and there is also variance in the indications and the number of treatments offered to patients across India [6].

- Medical insurance companies have always had this parallel and lopsided attitude towards psychiatric patients and their insurance rights. This may also stem from the fact that many corporate hospitals do not have a dedicated psychiatric unit and dedicated psychiatric wards. They even do not promote mental health and psychiatry like they may do for bariatric surgery, cancer, cardiology, cardiac surgery and nephrology. The failure to integrate mental health care under primary health care, despite the concerted efforts of the policy makers, is a barrier for insurance coverage in the right of patient care [7].

- There are several national and state mental health programmes that are initiated by the government in order to amplify mental health awareness and make people avail mental health care at cost effective measures, however, the stronghold of stigma continues to 
prevail and not all welfare programmes manage to provide for affordable care. Researchers also claim that the prohibitive cost of treatment is one of the major reasons for low effective demand for mental healthcare among low income households [8].

- The scope of earning for medical insurance companies, their agents and patients has been documented in medical sciences where inflated bills are presented to medical insurance companies and the cost issued back to the patient is shared between the patient, hospital and insurance agent. This has even been more with the advent of cashless insurance policies. The scope of this bill inflation is possible with manipulation of bills in medical and surgical specialties where even medicine bills may be inflated but the same is probably not possible in psychiatry [9].

- Medical sciences have always offered step motherly treatment to psychiatry where psychiatry has been treated as the 'Cinderella' of medical specialties which has not yet found its prince charming. This has also been seen in medical conferences and in funding grants received by government hospitals.

- The government and ministry of health care has also been partial to psychiatry. This stems from the meager allocation of the health care $(0.06-1 \%$ of the total health care budget) budget to mental health that even may make insurance companies feel that it is a negligible component of health care.

- We wish to exhort insurance companies that mental health is important and access to mental health care is a fundamental human right (as very much part of health) itself. There is a need for medical insurance companies to look at psychiatry and mental health. Disorders like depression and schizophrenia need attention from the health sector and there is a need for insurance companies to reduce the cost burden which is now fully on the patient. There is a need for psychiatric patients to get the basic rights to mental health care they deserve.

- Psychiatry is a neglected medical specialty and there is a dearth of psychiatrists and psychologists with a ratio of 1 psychiatrist per 2 lakh of the population with where the need is 1 per 10,000 with far lesser psychologists and counselors. There is also a scatter of psychiatrists that varies across the states with some states having higher and lower density of psychiatrists. This is coupled with a huge deficiency of psychiatric in-patient beds across the country [10].

- Medical insurance for psychiatry is now even more a necessity in the light of the new Mental Health Care Act that has been made keeping in mind the basic rights of the mentally ill and however insurance is missing from the Act [11].

- The Rashtriya Swasthya Bima Yojana (RSBY) is a general health insurance program of the central government aimed at families living on incomes below the poverty line, and it also covers the medical needs of mental illnesses. However, the psychiatric ramifications of medical illnesses do not get covered for under for insurance even if the insurance is for medical illnesses. There is also neglected covered care for the remaining population [12].

- With $7.5 \%$ of our nation battling with mental health problems, India being informally stratified as one of the most depressed nations globally and the constant rise in mental health burden, it is time that policy makers, judiciary benches and insurance companies wake up to the need [13].

- The status of covering mental health care under insurance has received attention with Insurance Regulatory and Development Authority of India (IRDAI) asking insurance companies to make provisions to cover mental illness, in a circular dated 16 August 2017, though nothing in implementation for 6 months now [14]. We hope that medical insurance companies would take the plunge into psychiatry and help psychiatric patients get their due of supported care which they deserve, which they till now have seemingly been deprived of. The health care ministry also needs to step up for the same and bring out bills and laws that shall enable them to get their due care. 


\section{REFERENCES}

1. Reddy KS, Patel V, Jha P, Paul VK, Kumar AS, Dandona L, Lancet India Group for Universal Healthcare. Towards achievement of universal health care in India by 2020: a call to action. Lancet 2011;377(9767):760-8.

2. Gururaj G, Varghese M, Benegal V, Rao GN, Pathak K, Singh LK, Misra R. National mental health survey of India, 2015-16: Summary. Bengaluru: National Institute of Mental Health and Neurosciences; 2016.

3. Saxena S, Thornicroft G, Knapp M, Whiteford H. Resources for mental health: scarcity, inequity, and inefficiency. Lancet 2007;370(9590):878-89.

4. Reddy MS. Depression: the disorder and the burden. Indian J Psychol Med $2010 ; 32$ (1):1-2.

5. Jeremy Sugarman MD, Sulmasy DP. Methods in Medical Ethics. Georgetown University Press; 2010.

6. Chanpattana W, Kramer BA, Kunigiri G, Gangadhar BN, Kitphati R, Andrade C. A survey of the practice of electroconvulsive therapy in Asia. J ECT 2010;26(1):5-10.

7. Patel V, Belkin GS, Chockalingam A, Cooper J, Saxena S, Unützer J. Grand challenges: integrating mental health services into priority health care platforms. PloS Med 2013;10(5):e1001448.

8. Maulik PK, Devarapalli S, Kallakuri S, Tewari A, Chilappagari S, Koschorke M, Thornicroft G. Evaluation of an anti-stigma campaign related to common mental disorders in rural India: a mixed methods approach. Psychol Med 2017;47(3):565-75.

9. Bhattacharjya AS, Sapra PK. Health insurance in China and India: segmented roles for public and private financing. Health Affairs 2008;27(4):1005-15.

10. Thirunavukarasu $\mathrm{M}$, Thirunavukarasu $\mathrm{P}$. Training and national deficit of psychiatrists in India-A critical analysis. Indian J Psychiatry 2010;52(Supp11):S83-8.

11. Sachan D. Mental health bill set to revolutionise care in India. Lancet 2013;382(9889):296.

12. Khurana S, Sharma S. National Mental Health Programme of India: a review of the history and current scenario. Int J Commun Med Pub Health 2016;3(10):2696-704.

13. Srivastava K, Chaterjee K, Bhat PK. Mental health awareness: the Indian Scenario. Industr Psychiatry J 2016;25(2):131-4.

14. Patel V. Global mental health: from science to action. Harv Rev Psychiatry 2012;20(1):6-12.

Acknowledgements - Nil

Source of Funding - Nil

Conflict of Interest $-\mathrm{Nil}$ 